of the skin and from want of use, the left leg appeared to be about what might be supposed to be half its natural circumference. By the contraction in the process of cicatrisation and by the assistance of smaller skin grafts, at the end of ten years the wound had entirely healed with the exception of two or three small fissures; these remained with rounded, thickened, and indurated edges. The right leg, which had been less severely injured, was also much diminished in size.

CASE 2.-A patient being treated for ascites in one of the medical wards of St. George's Hospital had an umbilical hernia. This when distended was the size of a small orange. The hernia was easily reduced and the sac left empty. Three hare-lip needles were introduced through the neck of the sac and a figure-of-8 ligature applied loosely over the extremities of each. After two or three days the needles were removed, and firm adhesion at the neck of the sac appeared to have taken place. The skin which had covered it became shivelled, of dusky brown colour, and remained the size of a small nut. So far as could be known there was no return of the hernia. A drawing of the parts by Dr. Westmacott as they were left after the operation is preserved.

CASE 3.-A gentleman had been treated for some two years and a half for dysentery. As there was some irritation about the rectum, I examined it. A bone, which subsequently proved to be a fish-bone, about two inches and a half long, was found to be impacted across the bowel about two inches from its orifice. By means of a long pair of forceps one end of the bone was got into a speculum. The bone was then withdrawe without difficulty. The symptoms from which this patient had so long suffered immediately ceased.

\section{PASTEUR'S PREVENTIVE TREATMENT FOR HYDROPHOBIA.}

By Hy. Tomkins, M.D., B.Sc.,

MEDICAL OFFICER OF HEALTH, LEICESTER.

PERHAPs one of the most reasonable objections made to the treatment by Pasteur of persons bitten by rabid animals, or rather, one may say, to the results recorded by him of such treatment, has been the fact that in a considerable number of the cases treated, evidence that the animal by which the patient had been bitten was actually and undoubtedly rabid is not forthcoming, and opponents have not been slow to urge that it is highly probable in many instances patients have undergone treatment when the dog which had inflicted the bite was quite healthy, or, at least, not suffering from rabies. In the following record of three cases treated at the Pasteur Institute last year it is placed beyond all doubt that the animal, at the time of inflicting the injuries, was suffering from rabies. On Jan. 8th, 1890, a stray dog came into the borough of Leicester from the adjoining suburbs and on its way bit two school children, a boy and a girl, on the face and hands, the wounds upon each of the children's faces being of a very extensive, lacerated character. This occurred outside the borough boundaries, and almost at the same time it bit also a small terrier dog. Continuing it course into the town it bit a young man severely on the hand, and shortly after this it was killed. The patients were seen by medical men and the wounds cauterised, but not until after the lapse of some little time; in one case nearly an hour elapsed. I saw all the patients on the tollowing day, and, with the assistance of Mr. Fraser, the veterinary inspector to the corporation, made a postmortem examination of the dog. The pathological appearances to the naked eye were practically nil, but the stomach contained some pieces of straw and other débris. The cord and medulla were removed. On Saturday, the Ith, I took the three patients to Paris (taking with me the cord removed from the dog), and on Sunday morning they were seen by M. Pasteur, and treatment commenced in the asual manner. From the cord several rabbits were inoculated, and before the end of a week these succumbed to what M. Pasteur declared to be rabies, The man was kept under treatment fourteen days, but the two children, owing to the severity of the wounds, were kept for twenty-five days before being sent home. The small terrier bitten by the dog was kept by me under close observation shut up, away from all other animals, and on the fifteenth day from being bitten it began to show signs of indisposition (having in the interval been apparently in good health), which soon declared itself as undoubtedly rabies, and the animal succumbed on the third day from the first onset of the symptoms. Being kept secluded and alone, it showed but few signs of excitement, but crawled about, refusing to eat or respond when called to, paralysis of the lower jaw and hind limbs soon supervening. It should be noted that the wound on its hind leg was but a small one, not larger than a threepennypiece, and at the time of its death was healed.

Here, then, we have indisputable evidence that the animal which bit these three patients was suffering from rabies, and the probabilities are, seeing how easily the second dog was infected, that at least one or other of the three would have developed symptoms of hydrophobia if the treatment for prevention had not been adopted. As more than twelve months have now elapsed since the occurrence, and all of them remain in good health, we may conclude they have now quite escaped from any untoward consequences.

Leicester.

\section{NOTE ON TRAUMATIC CEPHALHYDROCELE.}

By R. Clement Lucas, B.S., F.R.C.S.,

SURGEON TO GUY'S HOSPITAL, AND TO THE EYELINA HOSPITAL YOR CHILDREN.

IN THE LANCET of January 10th, under the title of "Traumatic Encephalo-meningocele," an interesting case is reported by Mr. H. Burton of a child who, after a severe injury to the head, developed a pulsating tumour of the scalp containing cerebro-spinal fluid. The writer, in his remarks, states that "it differs entirely from the traumatic meningocele described by $\mathrm{Mr}$. Clement Lucas and Mr. Golding-Bird." So far from this being the case, it is precisely of the kind which falls within that category; and had the writer found the opportunity of referring to the original papers, I think he could not have failed to be struck with the resemblance. . The only difference, indeed, lies in the fact that in his case the fracture was in the first place compound; but the primary union of the wound which took place allowed the fluid to accumulate beneath the scalp as if that covering had not been torn. Little was known of these rare and interesting tumours till the publication of my first case with a drawing in the Guy's Reports of 1876 , and the pathological conditions requisice for the production of the tumour were not understood. Subsequent years placed two post-mortem examinations within my reach, which are related in the volumes of the Gruy's Hospital Reports for 1878 and 1884, and I was able to show that these subcutaneous Hluid tumours communicated directly with the ventricles of the brain, and I further ventured the statement, based upon the study of these and other cases, that they could only be developed in childhood. Mr. Golding-Bird, in reporting a case in the Guy's Hospital Reports for 1889 , gives his own experience in support of my contention. Another very remarkable circumstance which often happens in these cases is a rapid absorption of the bone in the neighbourhood of the fracture, and as a consequence a permanent pulsating mass with heaped up and everted edges of bone may in some cases remain. Such conditions were found in cases reported by $\mathrm{Mr}$. T. Smith, Mr. Godlee, and Mr. Silcock. The escape of the flaid from the ventricular cavity is apparently secondary, to an increased secretion resulting from inflammation of its lining membrane and absorption of the damaged brain tissue along the track of the injury, for the fluid is seldom noticed till some days after the accident. The tern traumatic cephalhydrocele would seem preferable to traumatic encephalo-meningocele or meningocele, as the meninges and the brain are both perforated, and do not cover the cyst. As regards treatment, I am convinced that the less done in the way of active interference the better. Aspiration may be used for diagnostic purposes, but can be of little service to the patient, for the fluid invariably re-collects. Pressure during the inflammatory stage may lead to grave symptoms, as in the case detailed. The surgeon should bear in mind the very serious laceration that has taken place in the brain substance, and should ensure absolute quiet and brain rest for a lengthened period. In the 